\title{
Mutant Strains of Aerobacter aerogenes which Require both Methionine and Lysine for Aerobic Growth
}

\author{
By A. H. STOUTHAMER \\ Botanical Laboratory, Microbiology Department, Free University, \\ De Boelelaan 1087, Amsterdam, The Netherlands
}

(Accepted for publication 14 October 1966)

\begin{abstract}
SUMMARY
Two types of mutants of Aerobacter aerogenes were obtained which grow anaerobically in a minimal medium with glucose as sole carbon source, but which require either succinate or methionine + lysine for aerobic growth in this medium. Only one type of mutant grew in minimal medium with succinate as sole carbon source. This type accumulated pyruvate and $\alpha$-oxoglutarate during growth in minimal medium with glucose and succinate. It is apparently blocked in the oxidation of $\alpha$-oxoacids. The other type of mutants accumulated only $\alpha$-oxoglutarate during growth in minimal medium with glucose and succinate. Cell-free extracts of this type of mutant did not contain $\alpha$-oxoglutarate dehydrogenase and washed organisms were unable to oxidize acetate. The aerobic molar growth yield of the mutant in minimal medium with glucose, methionine and lysine was much smaller than that of the wild type. Anaerobic growth of these mutants was strongly inhibited by nitrate; this inhibition was prevented by the addition of succinate.
\end{abstract}

\section{INTRODUCTION}

During the isolation of auxotrophic mutants of Aerobacter aerogenes a number of mutants were observed, which did not grow with glucose as sole carbon source in a minimal medium under aerobic conditions. Upon anaerobic incubation, however, these mutants were able to grow in the same medium. Aerobic growth occurred when the medium was supplemented with both methionine and lysine. One group of mutants lacked $\alpha$-oxoglutarate dehydrogenase, the other group is blocked in the oxidation of $\alpha$-oxoacids in general. These mutants were used to study the influence of the citric acid cycle on energy production by growing cells and on the mode of formation of succinyl-CoA during nitrate respiration.

\section{METHODS}

Bacteriological methods. The strain of Aerobacter aerogenes was that used in previous studies (Hadjipetrou, Gerrits, Teulings \& Stouthamer, 1964 and Hadjipetrou \& Stouthamer, 1965). The minimal medium and the growth conditions were as described previously (Hadjipetrou et al. 1964). Mutations were induced by treating the bacteria with $N$-methyl- $N$-nitroso- $N^{1}$-nitroguanidine by the method of Stouthamer, de Haan \& Nijkamp (1965). Auxotropic mutants were enriched by the penicillin selection technique using the modification of de Haan, Stouthamer, Felix \& Mol (1963) and were screened in the normal way for their specific requirements. 
Enzyme assays. Extracts were prepared by submitting suspensions (approx. $2 \mathrm{~g}$. wet weight $/ 10 \mathrm{ml}$. in $0.01 \mathrm{M}$-phosphate buffer $\mathrm{pH} 6.8$ ) to ultrasonic oscillation in a Mullard ultrasonic disintegrator $(60 \mathrm{~W}$., $20 \mathrm{kcyc}$. $/ \mathrm{sec}$.) for $5 \mathrm{~min}$. The resultant suspension was centrifuged at $12,500 \mathrm{~g}$ for $30 \mathrm{~min}$. in an MSE 18 centrifuge at $4^{\circ}$. $\alpha$-Oxoglutarate dehydrogenase was assayed in the supernatant using the method described by Sanadi, Littlefield \& Bock (1952) with ferricyanide as oxidant.

Manometric experiments. Oxidations with resting cells were measured by conventional Warburg techniques with about $15 \mathrm{mg}$. dry weight cells per vessel.

Analytical methods. Glucose was estimated with a Biochemica Test Combination, containing glucose oxidase and peroxidase (C. F. Boehringer and Soehne GMBH). Pyruvate and $\alpha$-oxoglutarate were estimated with 2,4-dinitrophenylhydrazine according to the method of Reekers (1964). Protein was estimated with the Folin-Ciocalteu reagent (Lowry, Rosebrough, Farr \& Randall, 1951) using bovine serum albumin as a standard.

\section{RESULTS}

Growth experiments. The growth of wild-type Aerobacter aerogenes and the mutants 19 and 42 on different media with fairly large inocula is shown in Table 1. It is evident that, for aerobic growth, mutants 19 and 42 are dependent on succinate. Other citric acid cycle intermediates or glutamate cannot replace succinate. Succinate can be replaced, however, by both methionine and lysine or methionine and diaminopimelic acid. It is known that succinyl-CoA is required for the biosynthesis of these amino acids and succinylated intermediates occur in these biosynthetic pathways (Rowbury \& Woods, 1964; Gilvarg, 1957). From the results in Table 1 it seems likely that the

Table 1. Growth of wild-type Aerobacter aerogenes and the mutants 19 and 42 under different growth conditions

Aerobic incubation was in flasks with $8 \mathrm{ml}$. of medium; anaerobic incubation was in $12 \mathrm{ml}$. of medium. In both cases $0.2 \mathrm{ml}$. of washed cell suspension was used as inoculum.

Additions to minimal medium

Glucose

Glucose

Glucose+ succinate

Succinate

Citrate

Glutamate

Glucose + citrate

Glucose + glutamate

Fumarate

Glucose + fumarate

Glucose + methionine + lysine

Gas phase
Air
$95 \% \mathrm{~N}_{2}+5 \%$
$\mathrm{CO}_{2}$
Air
Air
Air
Air
Air
Air
Air
Air
Air

Wild
type

type

$$
\begin{gathered}
\text { Mutant } \\
42 \\
- \\
+ \\
+ \\
- \\
- \\
- \\
- \\
- \\
- \\
+
\end{gathered}
$$

other citric acid cycle intermediates cannot be transformed into succinyl-CoA under aerobic conditions. Mutants 19 and 42 differ only in their growth response to succinate, only mutant 19 being able to use this compound as sole carbon source. Our mutants resemble mutant N309-1 of Escherichia coli described by Davis, Kornberg, Nagler, Miller \& Mingioli (1959). The only difference is that this mutant requires 
threonine in addition to methionine and lysine for aerobic growth. Threonine was not necessary for the growth of our mutants. Back \& Westaway (1962) also studied a mutant of $E$. coli, which requires both methionine and lysine or methionine and diaminopimelic acid for aerobic growth. They found that methionine and lysine only permitted growth when fairly large inocula of washed organisms were used. Similar results were obtained for mutant 42 . With small inocula in liquid medium a long lag phase was found. An inoculum of $0.003 \mathrm{ml}$. of washed suspension in $8 \mathrm{ml}$. growth medium had a lag phase of $6.5 \mathrm{hr}$ before growth started. With even smaller inocula longer lag phases resulted and with inocula of less than $0.0001 \mathrm{ml}$. of washed suspension sometimes no growth was observed after $24 \mathrm{hr}$. Methionine and diaminopimelic acid had the same effects on the lag phase, when small inocula were used, as did methionine and lysine. On solid medium with methionine and lysine, mutants 19 and 42 produced very small colonies after $24 \mathrm{hr}$, whereas the mutants of Back \& Westaway (1962) do not produce visible colonies on this medium at all. These results show that methionine and lysine (or diaminopimelic acid) are not sufficient to overcome completely the metabolic block in mutants 19 and 42 and in the E. coli mutant of Back \& Westaway (1962).

Table 2. Oxidation of a number of substrates by resting cells of wild-type Aerobacter aerogenes and the mutant 19 and 42 grown on different media

The amount of substrate in the Warburg vessels was $10 \mu$ moles. The figures indicate the oxygen uptake in moles/mole substrate. The sign $>$ indicates that the reaction was not finished when the experiment was stopped after $180 \mathrm{~min}$. All the figures have been corrected for endogenous $\mathrm{O}_{2}$ uptake. The amount of cells in the vessels was approximately $15 \mathrm{mg}$. dry weight. Growth media: (1) nutrient broth + glucose, $0 \cdot 2 \%$ (2) nutrient broth (3) nutrient broth + citrate, $0 \cdot 2 \%$ (4) minimal medium + glucose, $0 \cdot 2 \%+$ methionine, 20 $\mu \mathrm{g} . / \mathrm{ml}$. + lysine, $20 \mu \mathrm{g} . / \mathrm{ml}$. (5) minimal medium + glucose, $0 \cdot 2 \%+$ succinate, $0 \cdot 24 \%$.

\begin{tabular}{|c|c|c|c|c|c|}
\hline & & & owth medi & & \\
\hline & 1 or 2 & 1 or 2 & 1,4 or 5 & 2 & 3 \\
\hline & Wild & Mutant & & Mutant & \\
\hline Glucose & $2 \cdot 70$ & 1.06 & $1 \cdot 27$ & $2 \cdot 50$ & $1 \cdot 21$ \\
\hline Acetate & $1 \cdot 10$ & 0 & 0 & 0.72 & $1 \cdot 12$ \\
\hline Citrate & $>2 \cdot 10$ & $>0.07$ & $>0.14$ & 0.65 & $>1.65$ \\
\hline Succinate & $>1 \cdot 89$ & $0 \cdot 55$ & 1.47 & 1.95 & 1.09 \\
\hline Pyruvate & $0 \cdot 84$ & $0 \cdot 31$ & $0 \cdot 39$ & $>1 \cdot 17$ & 一 \\
\hline L-malate & 一 & $0 \cdot 57$ & 0.55 & $1 \cdot 13$ & - \\
\hline$\alpha$-Oxoglutarate & - & 0 & 0 & - & $>0.37$ \\
\hline
\end{tabular}

The results in Table 1 suggest that mutants 19 and 42 are blocked in the aerobic formation of succinyl-CoA. It is known that succinyl-CoA is not only involved in the biosynthesis of methionine and lysine, but also in the biosynthesis of porphyrins (for review, see Lascelles, 1962). Therefore the effect of adding $\delta$-aminolaevulinic acid (5 $\mu \mathrm{g} . / \mathrm{ml}$.) or haemin $(1 \mu \mathrm{g} . / \mathrm{ml}$.) to the medium with methionine and lysine on the growth rate of cultures with a large inoculum or on the length of the lag with a small inoculum was tested. However, these additions were without effect.

Oxidation by resting cells. The final oxygen uptake by resting cells of wild-type Aerobacter aerogenes and mutants 19 and 42 grown under different conditions for a number of substrates are given in Table 2. Cells of mutant 42 never oxidize acetate. This is the result we expect when the formation of succinyl-CoA from other citric acid 
cycle intermediates is blocked. The oxidation of acetate by resting cells of mutant 19 depends on the medium on which the cells had been grown. The oxidation of some substrates by glucose nutrient broth-grown cells of mutant 19 is shown in Fig. 1. These cells do not oxidize acetate and the other substrates are oxidized with very low oxygen uptakes. The oxidation of the same substrates by nutrient broth-grown cells is shown in Fig. 2. These cells oxidize acetate and the oxygen uptakes for the other substrates are much higher than in the experiment with glucose nutrient broth-grown cells. Thus there is a large difference in the oxidative capacities of cells grown in different media. Such differences were not found for mutant 42; cells grown in all the media had the same oxidative capacities.

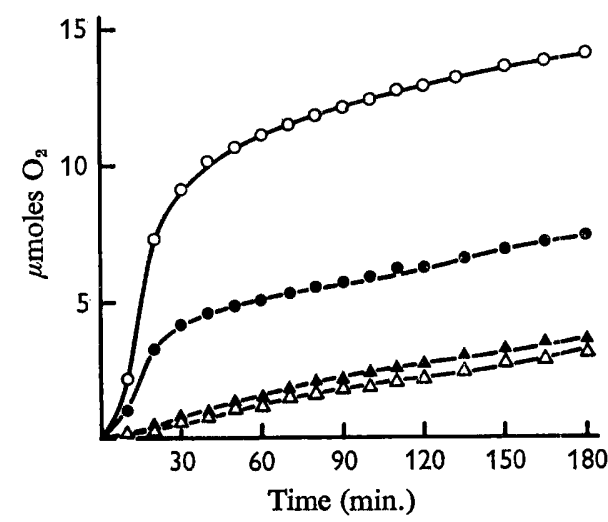

Fig. 1

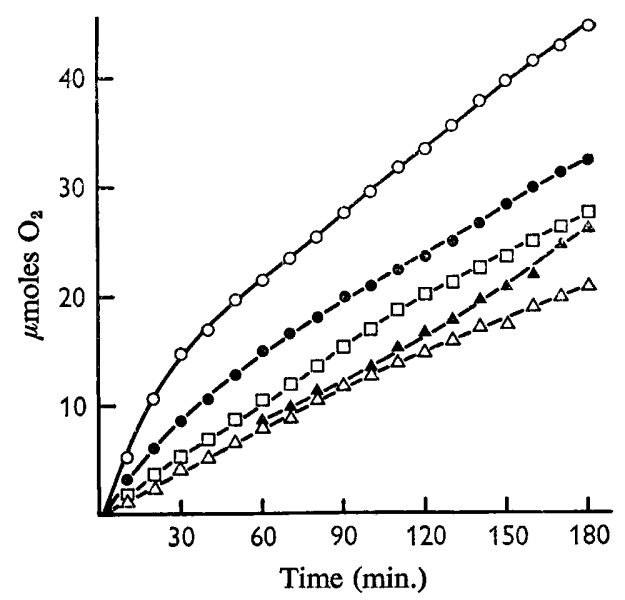

Fig. 2

Fig. 1. Oxidation of a number of substrates by glucose-nutrient broth grown cells of mutant 19 of Aerobacter aerogenes. The Warburg vessels contained $10 \mu$ moles substrate and $15 \mathrm{mg}$. dry weight cells. The curves have not been corrected for endogenous respiration. $\mathrm{O}-\mathrm{O}$ glucose; - pyruvate; $\boldsymbol{\Delta}-\mathbf{\Delta}$ citrate; $\Delta-\Delta$ endogenous and acetate.

Fig. 2. Oxidation of a number of substrates by nutrient broth grown cells of mutant 19 of Aerobacter aerogenes. Experimental conditions as in Fig. $1 . \square-\square$ acetate; $\triangle-\triangle$ endogenous; $\mathrm{O}-\mathrm{O}$ glucose; - pyruvate; $\boldsymbol{\Delta}-\mathbf{A}$ citrate.

Accumulation of $\alpha$-oxoacids. The previous results suggest that mutants 19 and 42 are blocked in the formation of succinyl-CoA. Davis et al. (1959) showed that mutant $\mathrm{N} 309-1$ of Escherichia coli, had similar properties to our mutants and did not contain $\alpha$-oxoglutaratedehydrogenase, therefore it seemed worthwhile to investigate the presence of this enzyme in our mutants. We can expect that when this enzyme is absent $\alpha$-oxoglutarate will accumulate during the oxidation of a suitable substrate. Therefore the formation of $\alpha$-oxoglutarate from a mixture of succinate and acetate and from citrate was tested. The results are shown in Table 3. During the experiments with mutant 19 using succinate and acetate we observed that there was also an accumulation of pyruvate. Therefore the formation of pyruvate and $\alpha$-ketoglutarate during growth in minimal medium with glucose and succinate was tested. The result shown in Fig. 3 indicates that during growth large amounts of pyruvate and $\alpha$-oxoglutarate are formed, which disappear again when the glucose has been fully utilized. Similar results were obtained when a large amount of washed suspension was inoculated into minimal 
medium with glucose. In some experiments we have also measured the amount of acetate formed in these experiments. The results show that acetate is accumulated, but also disappears after growth has stopped. Thus there is a difference between the behaviour of resting cells after growth on these media (Table 1) and the behaviour of growing cells in these media. No accumulation of pyruvate by growing or resting cells of wild type $A$. aerogenes or of mutant 42 could be detected. We must conclude therefore, that mutant 19 is blocked in the oxidation of $\alpha$-oxoacids in general and mutant 42 only in the oxidation of $\alpha$-oxoglutarate.

Table 3. Accumulation of $\alpha$-oxoglutarate by resting cells of the mutants 19 and 42 of Aerobacter aerogenes during oxidation of mixtures of succinate and acetate or of citrate

The bacteria had been grown on nutrient broth + citrate, $0 \cdot 2 \%$. The amount of substrate was $10 \mu$ moles and the amount of bacteria about $15 \mathrm{mg}$. dry weight.

$\begin{array}{ccc}\text { Mutant } & \text { Substrate } & \begin{array}{c}\alpha \text {-Oxoglutarate } \\ \text { accumulation } \\ (\mu \text { moles } / \mathrm{ml} .)\end{array} \\ 19 & \text { Acetate }+ \text { succinate } & 1.92 \\ 42 & \text { Citrate } & 5 \cdot 80 \\ & \text { Acetate + succinate } & 1.18 \\ & \text { Citrate } & 0.68\end{array}$

Demonstration of $\alpha$-oxoglutarate dehydrogenase in cell-free extracts. It has been shown for Escherichia coli that the oxidation of $\alpha$-oxoglutarate to succinyl-CoA is a very complex reaction (Hager \& Kornberg, 1961), in which the first step is:

$$
\alpha \text {-oxoglutarate }+\mathrm{TPP} \rightleftarrows \text { (succinic semialdehyde) }-\mathrm{TPP}+\mathrm{CO}_{2} \text {. }
$$

Only this reaction has been measured. The oxidation of $\alpha$-oxoglutarate by cellfree extracts of mutants 19 and 42 is illustrated in Fig. 4. In extracts of mutant 42 the enzyme is absent. Thus this mutant has the same metabolic defect as mutant N309-1 of E. coli (Davis et al. 1959; Hager \& Kornberg, 1961). The enzyme was detected in extracts of mutant 19, grown on nutrient broth, nutrient broth + glucose and nutrient broth + citrate. No correlation was found between $\alpha$-oxoglutarate dehydrogenase activity and acetate oxidation, since resting cells grown on nutrient broth + glucose did not oxidize acetate and still contained the enzyme.

Growth yields of mutant 19 and 42 in minimal medium with glucose. Previously, Hadjipetrou et al. (1964) found that during growth with glucose, acetate accumulated and the acetate was oxidized after glucose had been completely consumed. Acetate oxidation after glucose consumption does not contribute to the dry weight of bacteria. We found some evidence that acetate oxidation in the presence of glucose did contribute to the dry weight of bacteria, but to what extent was not known. Therefore the molar growth yields in minimal medium with glucose and methionine and lysine, with glucose alone and with succinate plus glucose were determined for wild-type Aerobacter aerogenes and mutants 19 and 42 . The results shown in Table 4 indicate that in the absence of acetate oxidation the molar growth yield for glucose is decreased from $76 \cdot 1 \mathrm{~g}$. (wild type) to $45 \cdot 3 \mathrm{~g}$. (mutant 42 ). Thus the energy of acetate oxidation in the presence of glucose contributes significantly to the molar growth yield. The molar growth yields for mutant 19 are only somewhat smaller than for the wild type. This 
confirms the results of the experiments in which the accumulation of $\alpha$-oxoacids was tested. These experiments had shown that mutant 19 is able to oxidize glucose completely in a growth medium.

Nitrate respiration and nitrate assimilation by mutant 42 . It has been shown that mutants 19 and 42 can grow anaerobically in a minimal medium with glucose as sole

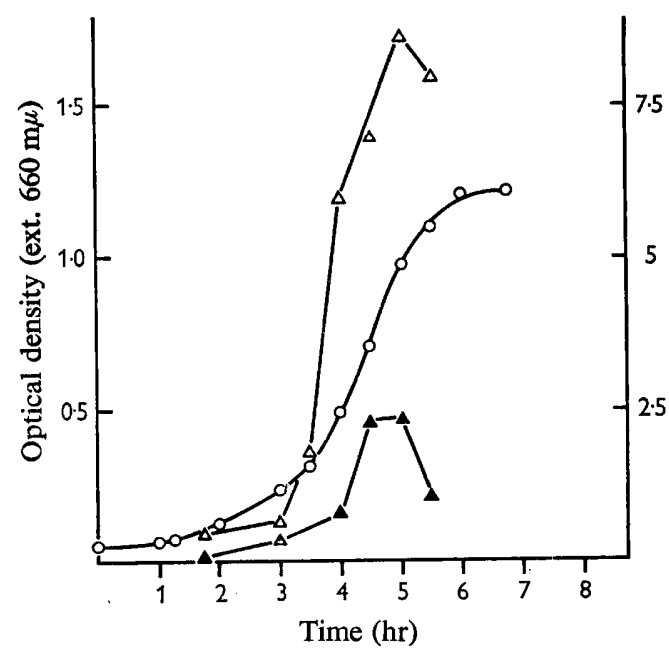

Fig. 3

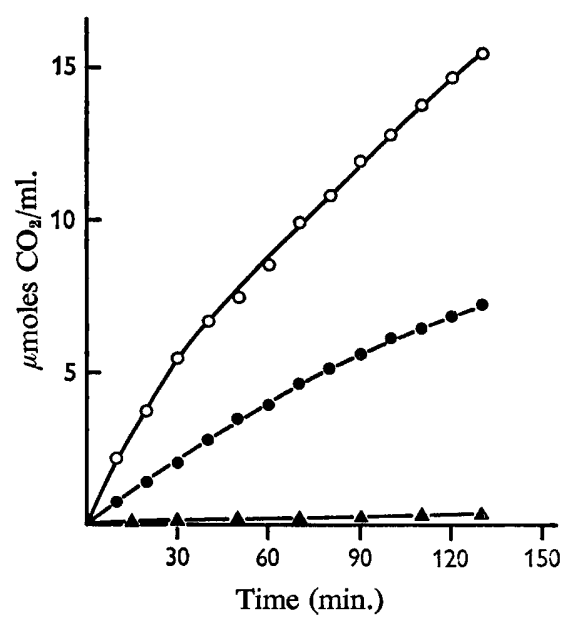

Fig. 4

Fig. 3. Accumulation of pyruvate and $\alpha$-oxoglutarate by mutant 19 of Aerobacter aerogenes, growing aerobically in minimal medium with glucose, $11 \cdot 1 \mu$ moles $/ \mathrm{ml}$. + succinate, 20 $\mu$ moles/ml.. After $5.5 \mathrm{hr}$ the glucose had been completely used. $\bigcirc-\bigcirc$ optical density of culture; $\triangle-\triangle$ pyruvate $(\mu \mathrm{moles} / \mathrm{ml}$.); $\Delta-\Delta \alpha$-oxoglutarate $(\mu \mathrm{moles} / \mathrm{ml}$.).

Fig. 4. Oxidation of $\alpha$-oxoglutarate by cell-free extracts of mutants 19 and 42 of Aerobacter aerogenes with ferricyanide as electron acceptor. The cells had been grown on nutrient broth + citrate, $0.2 \%$. The complete system in a Warburg vessel: $\alpha$-oxoglutarate, $50 \mu$ moles; $\mathrm{NaHCO}_{3}, 400 \mu$ moles; thiamin-pyrophosphate, $200 \mu \mathrm{g} ; \mathrm{MgCl}_{2}, 20 \mu$ moles; bovine serum albumin, $30 \mathrm{mg}$. and cell-free extract in a total volume of $1.9 \mathrm{ml}$. The sidebulb contained $0.1 \mathrm{ml}$ of $0.5 \mathrm{M}-\mathrm{K}_{3} \mathrm{Fe}(\mathrm{CN})_{6}$. The gas phase was $100 \% \mathrm{CO}_{2}$. The $\mathrm{CO}_{2}$ evolution was measured after tipping in the potassium ferricyanide. The incubation temperature was $37^{\circ}$. O-O cell-free, extract of mutant $19(1.9 \mathrm{mg}$. of protein); - cell-free extract of mutant $19(0.95 \mathrm{mg}$. of protein); $\Delta-\Delta$ cell-free extract of mutant $42(2.4 \mathrm{mg}$. of protein).

\section{Table 4. Molar growth yields of wild-type Aerobacter aerogenes and mutants 19 and 42}

The glucose concentration was $1.5 \mu \mathrm{moles} / \mathrm{ml}$; succinate concentration $5 \mu \mathrm{moles} / \mathrm{ml}$. The inoculum was $4 \mathrm{ml}$. of washed bacteria in $200 \mathrm{ml}$. of the indicated growth medium. $5 \mathrm{ml}$. samples were taken at intervals and the extinction at $660 \mathrm{~m} \mu$ was measured. The molar growth yields were calculated from the dry weights at the moment of maximal extinction. Dry weight was calculated from the previously established relationship: dry weight of bacteria $=380 \times$ extinction at $660 \mathrm{~m} \mu$ (Hadjipetrou et al. 1964).

$\begin{array}{llcc} & \text { Wild } & \text { Mutant } & \text { Mutant } \\ \text { Medium } & \text { type } & 19 & 42 \\ \text { cose } & 72 \cdot 1^{*} & 0 & 0 \\ \text { cose+succinate } & 76 \cdot 1 & 67 \cdot 5 & 45 \cdot 3 \\ \text { cose+methionine+lysine } & 77 \cdot 0 & 76 \cdot 6 & 44 \cdot 4\end{array}$

* From Hadjipetrou et al. (1964). 
carbon source. In this case succinyl-CoA is formed by reduction of oxaloacetate. We were interested to know how the cells satisfied their need for succinyl-CoA under anaerobic conditions in the presence of nitrate. It was found that mutant 42 gave very slow growth in a medium with nitrate as sole nitrogen source, in sharp contrast to the

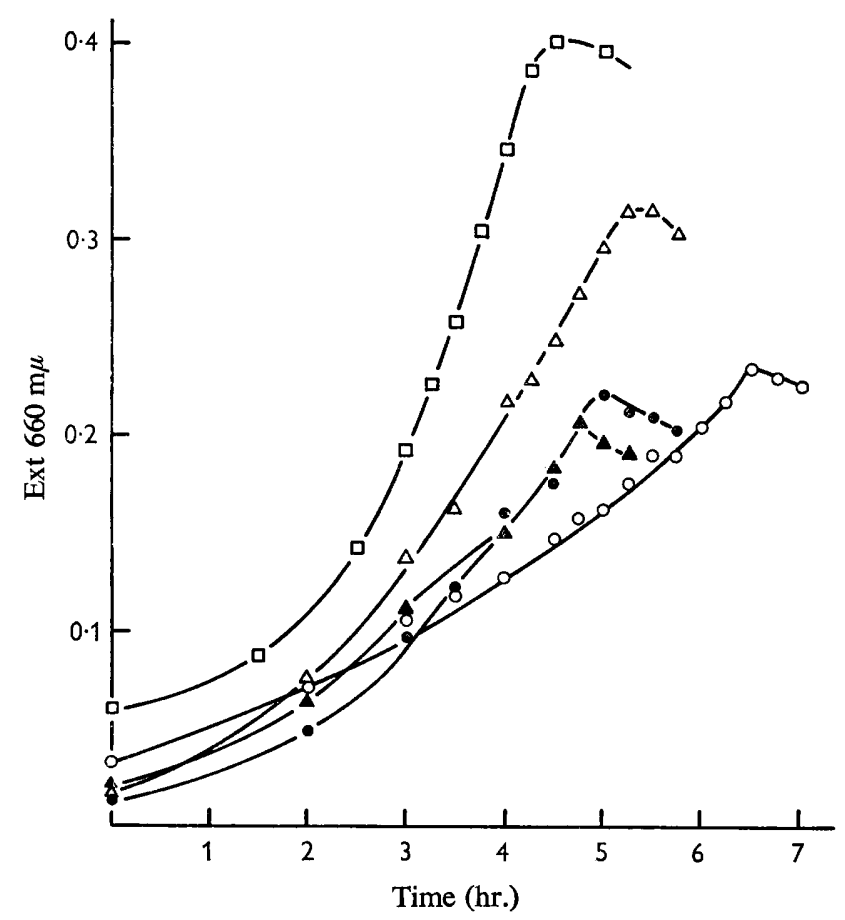

Fig. 5. Growth of cultures of wild-type Aerobacter aerogenes and of mutant 42, under anaerobic conditions with $3 \mu$ moles glucose $/ \mathrm{ml}$. in minimal medium, with different nitrogen sources. The gas phase was $95 \% \mathrm{~N}_{2}+5 \% \mathrm{CO}_{2}$. The inoculum was $20 \mathrm{ml}$. of washed bacteria in $200 \mathrm{ml}$. of the indicated growth medium. $5 \mathrm{ml}$. samples were taken at intervals and the extinction at $660 \mathrm{~m} \mu$ was measured. - mutant $42, \mathrm{NH}_{4} \mathrm{Cl}(0.2 \%) ; \triangle-\wedge$ mutant 42 , $\mathrm{NH}_{4} \mathrm{Cl}+$ succinate $\left(5 \mu\right.$ moles $/ \mathrm{ml}$.); $\triangle-\triangle$ mutant $42, \mathrm{KNO}_{3}+$ succinate; $\bigcirc-O$ mutant $42, \mathrm{KNO}_{3}(0 \cdot 35 \%) ; \square-\square$ wild type, $\mathrm{KNO}_{3}$.

Table 5. Molar growth yields of wild-type Aerobacter aerogenes and mutant 42 grown anaerobically with glucose under different conditions

The glucose concentration was $3 \mu \mathrm{moles} / \mathrm{ml}$., the succinate concentration $5 \mu \mathrm{moles} / \mathrm{ml}$. The inoculum was $20 \mathrm{ml}$. of washed bacteria in $200 \mathrm{ml}$. of the indicated medium. The molar growth yield was determined in Table 4.

Composition of minimal medium

\begin{tabular}{llrr}
\multicolumn{1}{c}{ C-source } & $\mathrm{N}$-source & $\begin{array}{c}\text { Wild } \\
\text { type }\end{array}$ & $\begin{array}{c}\text { Mutant } \\
42\end{array}$ \\
Glucose & $\mathrm{NH}_{4} \mathrm{Cl}$ & $26 \cdot 1^{*}$ & $26 \cdot 2$ \\
Glucose & $\mathrm{KNO}_{3}$ & $43 \cdot 0^{*}$ & $26 \cdot 6$ \\
Glucose & $\mathrm{KNO}_{3}+\mathrm{NH}_{4} \mathrm{Cl}$ & $45 \cdot 5^{*}$ & $29 \cdot 9$ \\
Glucose+succinate & $\mathrm{NH}_{4} \mathrm{Cl}$ & $28 \cdot 7$ & $23 \cdot 3$ \\
Glucose+ succinate & $\mathrm{KNO}_{3}$ & Not done & $37 \cdot 0$ \\
Glucose+ succinate & $\mathrm{KNO}_{3}+\mathrm{NH}_{4} \mathrm{Cl}$ & $48 \cdot 5$ & $38 \cdot 1$ \\
& * From Hadjipetrou \& Stouthamer (1965).
\end{tabular}


very good growth which the wild type shows under these conditions (Fig. 5). In this experiment a large inoculum of washed organisms was used. With smaller inocula the difference between the growth curves of the culture with ammonia and that with nitrate was much larger. In a separate experiment it was found that anaerobic growth in a medium with both nitrate and ammonia is slower than in a medium with only ammonia. This indicates that the slow growth with nitrate as sole nitrogen source is not due to slow assimilation of nitrate but to the fact that in its presence nitrate respiration occurs. Normal growth of mutant 42 in the presence of nitrate can be obtained when succinate is added (Fig. 5). These effects are not found with wild type Aerobacter aerogenes. The molar growth yields of wild type A. aerogenes and mutant 42 under these conditions are given in Table 5 . The molar growth yields of mutant 42 during anaerobic growth in the presence of nitrate are hardly larger than in its absence, in sharp contrast to the results with the wild type. The metabolic block in mutant 42 prevents the efficient use of nitrate respirations.

\section{DISCUSSION}

Experiments have shown that Aerobacter aerogenes mutant 42 is blocked in the decarboxylation of $\alpha$-oxoglutarate. The metabolic block in mutant 19 is unknown. Because the oxidation of both pyruvate and $\alpha$-oxoglutarate is impaired, we must look for a reaction which is involved in the oxidation of both compounds. The metabolic block in mutant 19 is not complete because in a growth medium glucose is completely oxidized (Table 4), whereas resting cells in some media do not oxidize glucose completely (Table 2). The reason for this difference in behaviour between growing and resting cells is not known. Experiments are in progress to define more clearly the metabolic block in mutant 19. When this is known the differences between growing and resting cells may become clear. Because the oxidation of pyruvate is retarded the flow of metabolites to the citric cycle is diminished, and because in addition the oxidation of $\alpha$-oxoglutarate is retarded the observed shortage of succinyl-CoA for biosynthetic purposes can be explained. A combination of methionine and lysine could not completely replace the requirement for succinate. Good growth in this medium was not obtained for the methionine- and lysine-requiring mutants of Escherichia coli, which were described by Back \& Westaway (1962). Haemin, which is derived from succinylCoA, did not improve growth in the presence of methionine and lysine. Haemin biosynthesis does not seem to be impaired in these mutants because cells grown on minimal medium with glucose, methionine and lysine (medium 4, Table 2) respire normally and preliminary experiments indicate that they contain normal levels of NADH oxidase. Two explanations may be offered for these observations: (1) Succinyl-CoA is not an intermediate in the biosynthesis of haemin in $A$. aerogenes, or (2) more likely the metabolic block in both mutants is leaky, permitting the synthesis of a small amount of succinyl-CoA, which is used preferentially for the biosynthesis of haemin. The results show, that poor growth in minimal medium with glucose, methionine and lysine is not due to a shortage of haemin. Two explanations for the poor growth in this medium may be given. (1) Succinyl-CoA is required for another unknown reaction, or (2) the combination of methionine and lysine produces repression of the aspartokinases, and perhaps of some other enzymes leading to a shortage of the aspartic acid family of amino acids (methionine, lysine, diaminopimelic acid, threo- 
nine and isoleucine). Repression of the enzymes involved in the biosynthesis of these amino acids in $E$. coli is very complex (Cohen \& Patte, 1963). This phenomenon may also explain the requirement for threonine by mutant N319-1 of E. coli (Davis et al. 1959). The experimental results are insufficient at this moment to permit a choice to be made between these possibilities.

The metabolic block in mutant 42 gives rise to a very sharp decrease in the molar growth yield with glucose, indicating that the energy of acetate oxidation contributes to the dry weight of bacteria, a fact which confirms a previous suggestion by Hadjipetrou et al. (1964). The molar growth yield of mutant 42 is about the same after aerobic growth as the yield obtained from wild type after anaerobic growth in the presence of nitrate (compare Tables 4 and 5). In Aerobacter aerogenes the citric acid cycle does not function anaerobically in the presence of nitrate (Pichinoty, Mottet, Bigliardi-Rouvier \& Forget, 1963: Hadjipetrou \& Stouthamer, 1965). The absence of $\alpha$-oxoglutaratedehydrogenase in mutant 42 also leads to a failure of the citric acid cycle. The fact that the molar growth yields of mutant 42 grown aerobically and of wild type grown anaerobically in the presence of nitrate, gives further support to our previous conclusion that nitrate respiration is as efficient as normal respiration (Hadjipetrou \& Stouthamer, 1965).

Mutants 19 and 42 can grow anaerobically in a minimal medium with glucose as sole carbon source. Succinate, which is formed by reduction of oxaloacetate, is a normal end product of glucose fermentation in this strain of Aerobacter aerogenes (Hadjipetrou, 1965). Succinate can be converted into succinyl-CoA and in this way the cells satisfy their need for succinyl-CoA. Anaerobic growth of mutant 42 is strongly inhibited by the presence of nitrate and this inhibition is prevented by the addition of succinate. In the presence of nitrate the hydrogen donor, necessary for the reduction of oxaloacetate to succinate, is reoxidized by nitrate. This explains the observation that addition of nitrate to an anaerobically growing culture causes a shortage of succinyl-CoA. These results indicate that the wild type grown anaerobically in the presence of nitrate forms succinyl-CoA by the oxidation of $\alpha$-oxoglutarate with nitrate as hydrogen acceptor. Thus although the citric acid cycle does not function to complete the oxidation of acetate under anaerobic conditions in the presence of nitrate, the cycle is utilized more extensively for biosynthesis than in the absence of nitrate. The reasons for the absence of anaerobic acetate oxidation in the presence of nitrate are being studied at this moment.

The author is very grateful to Miss A. K. Mol, Miss E. A. Spanjaerdt Speckman, Miss M. M. G. Schotanus, Miss Z. J. H. Kamphuis and Mr P. van der Zee for technical assistance.

\section{REFERENCES}

BACK, K. J. C. \& Westaway, E. G. (1962). Studies on a mutant strain of Escherichia coli which requires both methionine and lysine for growth. J. gen. Microbiol. $27,41$.

Cohen, G. N. \& PATTe, J. C. (1963). Some aspects of the regulation of amino acid biosynthesis in a branched pathway. Cold Spr. Harb. Symp. quant. Biol. 28, 513.

Davis, B. D., Kornberg, H. L., Nagler, A., Miller, P. \& Mingioli, E. (1959). Formation and functions of succinate in Escherichia coli. Fed. Proc. Fedn Am. Socs. exp. Biol. $18,211$.

GILvarg, C. (1957). $N$-succinyl-L-diaminopimelic acid, an intermediate in the biosynthesis of diaminopimelic acid. Biochim. biophys. Acta 24, 216. 
HaAn, P. G. DE, Stouthamer, A. H., Felix, H. S. \& Mol, A. K. (1963). Transfer of $F^{\prime}$ from Escherichia coli $\mathrm{K} 12$ to Escherichia coli $\mathrm{B}$ and to strains of Paracolobacter and Klebsiella. Antonie van Leeuwenhoek 29, 407.

HADJIPETROU, L. P. (1965). Relation between energy production and aerobic growth of bacteria. Thesis, Univ. of Utrecht.

Hadjipetrou, L. P. \& Stouthamer, A. H. (1965). Energy production during nitrate respiration by Aerobacter aerogenes. J. gen. Microbiol. 38, 29.

Hadjipetrou, L. P., Gerrits, J. P., Teulings, F. A. G. \& Stouthamer, A. H. (1964). Relation between energy production and growth of Aerobacter aerogenes. J. gen. Microbiol. 36, 139.

HAGER, L. P. \& Kornberg, H. L. (1961). On the mechanism of $\alpha$-oxoglutaratedehydrogenase in Escherichia coli. Biochem. J. 78, 194.

LASCELLES, J. (1962). Tetrapyrrole synthesis in microorganisms. In The Bacteria. Ed. by I. C. Gunsalus, and R. Y. Stanier. vol. 3, p. 335. New York: Academic Press.

Lowry, O. H., Rosebrough, N. J., FARR, A. L. \& RANDALl, R. J. (1951). Protein measurement with the folin phenol reagent. J. biol. Chem. 193, 265.

Pichinoty, F., Mottet, F., Bigliardi-Rouvier, V. J. \& Forget, P. (1963). Le cycle de Krebs chez les bactéries dénitrifiantes. $Z$. Naturforschg. $18 b, 492$.

REEKERS, A. (1964). On the production of $\alpha$-ketoglutaric acid by Pseudomonas reptilovora, Coldwell and Ryerson. Thesis, University of Delft.

ROWBURY, R. J. \& WooDs, D. D. (1964). O-succinyl-homoserine as an intermediate in the synthesis of cystathionine by Escherichia coli. J. gen. Microbiol. 36, 341.

SANadi, D. R., LitTlefield, J. W. \& Bock, R. M. (1952). Studies on $\alpha$-ketoglutaric oxidase. II. Purification and properties. J. biol. Chem. 197, 851.

Stouthamer, A. H., HaAN, P. G. DE \& NiskamP, H. J. J. (1965). Mapping of purine markers in Escherichia coli K12. Genet. Res. Camb. 6, 442. 